\title{
Association between coffee consumption and serum lipid profile
}

\author{
EFSUN KARABUDAK, DUYGU TÜRKÖZÜ and EDA KÖKSAL \\ Department of Nutrition and Dietetics, Faculty of Health Sciences, Gazi University, Ankara 06500, Turkey
}

Received July 16, 2014; Accepted January 30, 2015

DOI: $10.3892 /$ etm.2015.2342

\begin{abstract}
The aim of the present study was to investigate the association between coffee consumption and serum lipid levels in a study population of 122 Turkish subjects (mean age, $41.4 \pm 12.69$ years), including 48 males and 74 females. A questionnaire was compiled to determine baseline characteristics, and food and coffee consumption. Subjects were divided into three groups, which included non-drinkers, Turkish coffee and instant coffee drinkers, and anthropometric measurements were acquired, including weight, height and body mass index. Serum lipid levels were analyzed, including the total cholesterol (TC), triglyceride (TG), high-density lipoprotein cholesterol (HDL-C), low-density lipoprotein cholesterol (LDL-C) and very low-density lipoprotein cholesterol (VLDL-C) levels. Of the population studied, $76.2 \%$ had consumed at least one cup of coffee per week over the previous year. Daily consumption values were $62.3 \pm 40.60 \mathrm{ml}(0.7 \pm 0.50 \mathrm{cup})$ for Turkish coffee and $116.3 \pm 121.96 \mathrm{ml}(0.7 \pm 0.81$ cup) for instant coffee. No statistically significant differences were observed in the serum levels of TC, TG, LDL-C, HDL-C or VLDL-C among the three groups. In addition, no statistically significant differences were observed in the serum lipid levels when comparing individuals who consumed coffee with sugar/cream or who smoked and those who did not $(\mathrm{P}>0.05)$. Therefore, the present observations indicated no significant association between the consumption of Turkish or instant coffee and serum lipid levels.
\end{abstract}

\section{Introduction}

Coffee is one of the most widely consumed beverages worldwide $(1,2)$. However, the mean annual consumption of coffee in Turkey, which has a large population of $\sim 74$ million inhabitants, is only $0.4-0.7 \mathrm{~kg}$ per capita. By contrast, coffee

Correspondence to: Miss. Duygu Türközü, Department of Nutrition and Dietetics, Faculty of Health Sciences, Gazi University, 16 Yaşar Muammer Bostanci Street, Beşevler, Ankara 06500, Turkey

E-mail: duygu_turkozu@ymail.com

Key words: instant coffee, Turkish coffee, serum lipids, smoking, sweeteners consumption per capita is $11.7 \mathrm{~kg}$ in Finland, $8.1 \mathrm{~kg}$ in Sweden and $6.3 \mathrm{~kg}$ in the Netherlands (2).

Numerous methods of making coffee are used across the world, as reported by the International Coffee Organization (http://www.ico.org/making_coffee.asp),includingAraborTurkish, drip or filter, plunger or cafetière, espresso, cappuccino, moka-napoletana, percolator, soluble or instant and flavored coffee. Previous studies have indicated that coffee consumption may result in certain health benefits (3). To date, numerous in vitro studies, cell experiments, animal models, and epidemiological and human trials have suggested that acute or habitual coffee consumption may reduce the risk of mortality, cardiovascular disease, type 2 diabetes mellitus, obesity, liver disease and a number of degenerative diseases, such as Alzheimer's and Parkinson's, in addition to certain types of cancer $(4,5)$.

The effect of coffee consumption on serum lipid levels varies depending on the method of preparation and the type of coffee (6). Certain coffee preparation methods may result in increased serum total cholesterol (TC) and low-density lipoprotein cholesterol (LDL-C) levels $(7,8)$, whereas other methods do not $(9,10)$. For example, previous studies have indicated that increased consumption of unfiltered coffee results in a dose-dependent increase in serum levels of TC, LDL-C and triglycerides (TG) $(11,12)$. In addition to the quantity of coffee consumed, coffee consumption habits may affect the serum lipid levels. Coffee consumption combined with smoking is known to affect serum lipid levels. A previous study revealed that smoking while consuming coffee caused the atherogenic risk to increase synergistically, with increased serum LDL-C levels and reduced high-density lipoprotein cholesterol (HDL-C) levels (13). However, additional studies have not identified an increase in the risk of coronary heart disease as a result of this combination $(14,15)$.

To the best of our knowledge, there are a limited number of studies investigating the correlation between Turkish coffee consumption and serum lipid levels. Therefore, the present pilot study was conducted with the aim of assessing the association between the coffee consumption status, including the quantity, variety and habits, and serum lipid levels in Turkish individuals.

\section{Materials and methods}

Study population. The study was conducted between January and May 2012 in Ankara, Turkey. The subject population consisted of 122 subjects (48 males and 74 females) who were 
inhabitants of Ankara. Subject ages ranged between 18 and 75 years, with a mean age of $41.4 \pm 12.69$ years. Participants were required to meet the following criteria: No regular use of drugs or supplements with antioxidative or lipid-lowering properties, and no chronic diseases, including diabetes, coronary heart disease, cerebrovascular disease, hypothyroidism or other major diseases.

Ethical approval was obtained from the Faculty of Health Sciences of Gazi University (Ankara, Turkey). Clear explanations were provided for the patients with regard to the purpose of the study, after which written informed consent was obtained from all the subjects in accordance with the Declaration of Helsinki (World Medical Association).

Study design and setting. Subjects were required to respond to a questionnaire in order to determine their demographic characteristics, including age, education level and tobacco consumption. Anthropometric measures, including body weight $(\mathrm{kg})$ and height $(\mathrm{m})$, were obtained following the collection of blood samples from the participants. Body mass index (BMI) was calculated as the weight $/$ height ${ }^{2}\left(\mathrm{~kg} / \mathrm{m}^{2}\right)$, and was classified according to the BMI cut-off points adopted by the World Health Organization (http://apps.who.int/bmi/index.jsp?introPage=intro_3.html).A face-to-face interview method was used to collect the data for this cross-sectional study.

Food intake and coffee consumption. Two-day food records were compiled by dieticians and the daily intake of energy, carbohydrate, total fat, fat fractions, cholesterol, total protein and dietary fiber were evaluated using a Nutrient Data Base Program (BeBiS, version 7.0; Pasifik Company, Istanbul, Turkey), adapted for Turkish individuals. The status and quantity of coffee consumption, the duration of coffee consumption (years), and the frequency and habits for eight varieties of coffee (Turkish coffee, instant coffee, cappuccino, espresso, Mirra, frappe, espresso and iced coffee) consumed by coffee drinkers in the preceding one-year period were determined. Subjects were divided into three groups, classified as non-drinkers, Turkish coffee drinkers and instant coffee drinkers, and the baseline characteristics were compared among these groups. Coffee consumption frequencies were determined as follows: Multiple times per year to less than once per month, once per month, 2-3 times per month, once per week, 2-3 times per week, 4-6 times per week, once per day, 2-3 times per day and $>3$ times per day. In order to standardize the questionnaire responses, coffee cup volumes were defined as $80 \mathrm{ml}$ for Turkish coffee, $30 \mathrm{ml}$ for espresso and $150 \mathrm{ml}$ for all other varieties of coffee. Numerous factors, including coffee density/volume (dark, medium and clear), temperature, coffee consumption type (plain, milk or liquid/powder coffee cream and added sweeteners), factors affecting coffee consumption (season, working conditions and stress) and variations in consumption habits in response to these factors, were taken into consideration.

Assessment of serum lipid profiles. Venous blood was collected following overnight fasting by the subject to determine serum lipid levels. Serum concentrations of TC, TG, HDL-C, LDL-C and very low-density lipoprotein cholesterol (VLDL-C) were quantified (mM) at the Ankara Gulhane Military Medical Academy Hospital (Ankara, Turkey).

Statistical analysis. Results of the statistical analysis are expressed as the mean \pm standard deviation, frequencies and percentages. The Kolmogorov-Smirnov test was performed to determine the normality of the measurements. Standard descriptive statistics, the two-tailed Student's t-test, the $\chi^{2}$ test and Tukey's test, as appropriate, were used to compare the characteristics among the three groups. The Mann-Whitney U-test was used to compare non-normally-distributed values between the groups. In the statistical analysis, various factors, including age, gender, BMI, smoking, total energy, total fat, fat fractions, fiber intake and coffee consumption habits, were considered to be potential confounding factors, as described in previous studies $(7,9,13)$. Therefore, the effects of these variables on serum lipid levels were analyzed using multivariate analysis of covariance. $\mathrm{P}$-values were two-tailed and $\mathrm{P}<0.05$ was considered to indicate a statistically significant difference.

\section{Results}

Characteristics of the study cohort. Assessment of the subject demographic characteristics revealed that $46.7 \%$ were university graduates, $36.9 \%$ were high school graduates, $15.6 \%$ were primary school graduates and $0.8 \%$ were illiterate.

The mean BMI of the subject population was $27.8 \pm 4.8 \mathrm{~kg} / \mathrm{m}^{2}$. In total, $37.7 \%$ of the individuals were obese, $28.7 \%$ were overweight, $30.3 \%$ were of normal weight and $3.3 \%$ were underweight.

The prevalence of smoking was $22.1 \%$, and the mean number of the cigarettes smoked per day was $15.1 \pm 8.68$. The mean age for adopting a smoking habit was $19.1 \pm 83.93$ years and the mean duration of a smoking habit was $16.2 \pm 9.20$ years.

Coffee consumption habits. In total, $76.2 \%$ of the study population consumed at least one cup of coffee per week during the preceding year. The mean duration of consuming at least one cup of coffee per week was $14.3 \pm 8.46$ years. The estimated mean consumption of all types of coffee was $89.1 \pm 117.3 \mathrm{ml} /$ day. The daily consumption of the various types of coffee were as follows: Turkish coffee, $62.3 \pm 40.60 \mathrm{ml}(0.7 \pm 0.50 \mathrm{cup})$; instant coffee varieties, $116.3 \pm 121.96 \mathrm{ml}(0.7 \pm 0.81 \mathrm{cup})$; cappuccino, $47.9 \pm 68.82 \mathrm{ml}(0.3 \pm 0.45 \mathrm{cup})$; espresso, $6.1 \pm 0.75 \mathrm{ml}$ ( $0.2 \pm 0.02 \mathrm{cup})$; and filtered, $1.35 \pm 10.50 \mathrm{ml}(0.09 \pm 0.07 \mathrm{cup}$; Table I). No statistically significant differences were observed between genders in the daily consumption of each coffee variety ( $\mathrm{P}>0.05$; Table I). No subjects reported the consumption of any variety of decaffeinated coffee.

Numerous factors, including coffee density/volume (dark, $>2 \mathrm{~g}$ pure soluble coffee bean/150 ml water; medium, $2 \mathrm{~g}$ pure soluble coffee bean/150 ml water; and light, $<2 \mathrm{~g}$ pure soluble coffee bean $/ 150 \mathrm{ml}$ water), temperature (very hot, $>80^{\circ} \mathrm{C}$; hot, $70-80^{\circ} \mathrm{C}$; warm, $40-69^{\circ} \mathrm{C}$; and cold, $<40^{\circ} \mathrm{C}$ ), coffee consumption type (plain, milk or liquid/powder coffee cream and added sweeteners), factors affecting coffee consumption (season, working conditions and stress) and the variations in consumption habits in response to these factors, were taken into consideration. Subject temperature preferences were as follows: Hot (73.3\%), warm (21.8\%), very hot (4.0\%) and 
Table I. Daily consumption of various coffee types by gender.

\begin{tabular}{|c|c|c|c|c|c|c|}
\hline \multirow[b]{2}{*}{ Coffee type } & \multicolumn{2}{|c|}{ Females } & \multicolumn{2}{|c|}{ Males } & \multicolumn{2}{|c|}{ Total } \\
\hline & Volume (ml) & Cup & Volume (ml) & Cup & Volume (ml) & Cup \\
\hline Turkish & $66.9 \pm 39.38$ & $0.8 \pm 0.49$ & $56.7 \pm 42.5$ & $0.7 \pm 0.53$ & $62.3 \pm 40.60$ & $0.7 \pm 0.50$ \\
\hline Instant & $105.6 \pm 126.36$ & $0.7 \pm 0.84$ & $130.2 \pm 116.65$ & $0.8 \pm 0.77$ & $116.3 \pm 121.96$ & $0.7 \pm 0.81$ \\
\hline Cappuccino & $17.5 \pm 15.48$ & $0.1 \pm 0.10$ & $78.3 \pm 101.3$ & $0.5 \pm 0.67$ & $47.9 \pm 68.82$ & $0.3 \pm 0.45$ \\
\hline Espresso & $6.6 \pm 0.00$ & $0.2 \pm 0.00$ & $5.9 \pm 0.91$ & $0.1 \pm 0.03$ & $6.1 \pm 0.75$ & $0.2 \pm 0.02$ \\
\hline Filtered & $0.2 \pm 2.52$ & $0.001 \pm 0.16$ & $0.1 \pm 0.95$ & $0.0006 \pm 0.006$ & $1.35 \pm 10.50$ & $0.009 \pm 0.07$ \\
\hline
\end{tabular}

Data are expressed as the mean \pm standard deviation. $\mathrm{P}>0.05$. Cup sizes were $80 \mathrm{ml}$ for Turkish coffee, $30 \mathrm{ml}$ for espresso and $150 \mathrm{ml}$ for all other coffee types.

Table II. Energy and nutrient intake, and baseline characteristics of the three groups.

\begin{tabular}{|c|c|c|c|}
\hline Variables & Non-drinkers $(n=42)$ & Turkish coffee $(n=32)$ & Instant coffee $(n=48)$ \\
\hline \multicolumn{4}{|l|}{ Energy and nutrient intake } \\
\hline Total energy (MJ) & $7.6 \pm 1.96$ & $7.9 \pm 2.28$ & $7.6 \pm 2.10$ \\
\hline Protein $(\%)$ & $16.7 \pm 3.50$ & $15.7 \pm 2.95$ & $16.2 \pm 2.83$ \\
\hline Fat $(\%)$ & $35.2 \pm 7.26$ & $35.8 \pm 7.26$ & $34.9 \pm 9.88$ \\
\hline Saturated fat (\%) & $9.7 \pm 2.24$ & $10.2 \pm 2.61$ & $9.7 \pm 2.60$ \\
\hline Monounsaturated fat (\%) & $13.6 \pm 3.64$ & $13.9 \pm 3.32$ & $13.2 \pm 3.95$ \\
\hline Polyunsaturated fat (\%) & $9.9 \pm 2.97$ & $9.5 \pm 2.93$ & $10.1 \pm 3.65$ \\
\hline Omega 3 (g) & $1.7 \pm 1.10$ & $2.1 \pm 2.12$ & $1.8 \pm 1.55$ \\
\hline Omega $6(\mathrm{~g})$ & $17.9 \pm 5.82$ & $17.1 \pm 4.61$ & $17.9 \pm 9.97$ \\
\hline Cholesterol (mg) & $200.8 \pm 92.48$ & $212.8 \pm 87.17$ & $194.6 \pm 86.20$ \\
\hline Carbohydrate (\%) & $47.8 \pm 8.18$ & $48.4 \pm 7.58$ & $48.7 \pm 9.10$ \\
\hline Fiber $(\mathrm{g})$ & $24.8 \pm 7.76$ & $24.5 \pm 8.96$ & $24.1 \pm 9.10$ \\
\hline \multicolumn{4}{|l|}{ Baseline characteristics } \\
\hline Age (years) & $44.4 \pm 14.57$ & $42.3 \pm 10.73$ & $38.6 \pm 12.5$ \\
\hline Body mass index $\left(\mathrm{kg} / \mathrm{m}^{2}\right)$ & $28.9 \pm 4.89$ & $28.2 \pm 5.05$ & $28.9 \pm 4.74$ \\
\hline Black tea consumption (ml/day) & $360.4 \pm 250.25$ & $322.1 \pm 182.4$ & $445.9 \pm 346.9$ \\
\hline Herbal tea consumption (ml/day) & $26.1 \pm 69.60$ & $27.0 \pm 55.46$ & $17.5 \pm 50.33$ \\
\hline
\end{tabular}

Data are expressed as the mean \pm standard deviation. $\mathrm{P}>0.05$.

cold $(1.0 \%)$. A total of $78.2 \%$ of the subjects preferred coffee of medium intensity, $16.8 \%$ preferred dark coffee and $5.0 \%$ preferred their coffee light. In addition, $55.7 \%$ of the subjects regularly consumed cane sugar with coffee, while $59.4 \%$ preferred plain coffee and $40.6 \%$ added cream or a powdered substitute. Of the $10.3 \%$ of subjects who reported that their coffee consumption habits altered by season, $90.9 \%$ reported increased coffee consumption during the winter. In addition, $89.7 \%$ of the subjects stated that working conditions did not affect their coffee consumption, while $90.7 \%$ stated that their stress level did not affect their coffee consumption (data not shown).

Comparison of baseline characteristics, energy and nutrition intake among the non-drinkers, Turkish coffee and instant coffee groups. Baseline characteristics were grouped according to coffee consumption habits. The mean of age was $44.4 \pm 14.57$ years for non-drinkers, $42.3 \pm 10.73$ years for Turkish coffee drinkers and 38.6 \pm 12.5 years for instant coffee drinkers. Furthermore, the mean BMI values were $28.9 \pm 4.89 \mathrm{~kg} / \mathrm{m}^{2}$ for non-drinkers, $28.2 \pm 5.05 \mathrm{~kg} / \mathrm{m}^{2}$ for Turkish coffee drinkers and $28.9 \pm 4.74 \mathrm{~kg} / \mathrm{m}^{2}$ for instant coffee drinkers (Table II).

Evaluation of subject energy and nutrition intake indicated that the daily protein intake and polyunsaturated fat in the diets of the Turkish coffee drinkers was lower compared with the other groups. By contrast, the daily intake of carbohydrates, fat, saturated fat, monounsaturated fat, omega 3 and cholesterol were higher in the Turkish coffee group compared with the remaining two groups (Table II). However, one-way analysis of variance identified no statistically significant differences in the baseline characteristics or energy and nutrient intake among the participants in the three groups $(\mathrm{P}>0.05)$. Black tea consumption was higher in the instant coffee group 
Table III. Serum lipids levels (mM) of the three groups.

\begin{tabular}{lccc}
\hline Serum lipid & Non-drinkers $(\mathrm{n}=42)$ & Turkish coffee $(\mathrm{n}=32)$ & Instant coffee $(\mathrm{n}=48)$ \\
\hline Triglyceride & $2.0 \pm 1.10$ & $1.9 \pm 1.42$ & $2.7 \pm 3.87$ \\
Total cholesterol & $5.7 \pm 1.32$ & $5.8 \pm 1.33$ & $5.7 \pm 1.24$ \\
LDL-C & $3.5 \pm 1.18$ & $3.7 \pm 0.97$ & $3.3 \pm 1.12$ \\
HDL-C & $1.2 \pm 0.24$ & $1.2 \pm 0.31$ & $1.2 \pm 0.27$ \\
VLDL-C & $1.0 \pm 0.72$ & $0.8 \pm 0.36$ & $0.9 \pm 0.32$ \\
\hline
\end{tabular}

Data are expressed as the mean \pm standard deviation. Data were adjusted for confounding factors, including age, gender, smoking, body mass index, black and herbal tea consumption, daily total energy, total fat, polyunsaturated fat, monounsaturated fat, omega 3, omega 6, carbohydrate/fiber intakes, coffee consumption duration and habits $(\mathrm{P}>0.05)$. LDL-C, low-density lipoprotein cholesterol; HDL-C, high-density lipoprotein cholesterol; VLDL-C, very low-density lipoprotein cholesterol.

Table IV. Serum lipid levels (mM) of the subjects according to sugar/cream consumption and smoking status.

\begin{tabular}{|c|c|c|c|c|c|c|}
\hline \multirow[b]{2}{*}{ Serum lipid } & \multicolumn{2}{|c|}{ Added sugar } & \multicolumn{2}{|c|}{ Added cream } & \multicolumn{2}{|c|}{ Smoking status } \\
\hline & Never & Sugar & Never & Cream & Yes & No \\
\hline Triglyceride & $1.8 \pm 0.89$ & $2.6 \pm 3.38$ & $2.2 \pm 1.34$ & $2.6 \pm 4.16$ & $2.0 \pm 1.01$ & $2.3 \pm 2.94$ \\
\hline Total cholesterol & $5.6 \pm 1.34$ & $5.7 \pm 1.22$ & $5.9 \pm 1.21$ & $5.5 \pm 1.24$ & $5.7 \pm 1.14$ & $5.7 \pm 1.32$ \\
\hline LDL-C & $3.3 \pm 1.13$ & $3.5 \pm 1.06$ & $3.7 \pm 1.03$ & $3.1 \pm 1.07$ & $3.5 \pm 1.19$ & $3.5 \pm 1.18$ \\
\hline HDL-C & $1.3 \pm 0.28$ & $1.1 \pm 0.26$ & $1.2 \pm 0.27$ & $1.2 \pm 0.30$ & $1.2 \pm 0.33$ & $1.2 \pm 0.25$ \\
\hline VLDL-C & $0.8 \pm 0.35$ & $1.1 \pm 0.62$ & $1.0 \pm 0.60$ & $0.8 \pm 0.37$ & $0.9 \pm 0.19$ & $0.9 \pm 0.60$ \\
\hline
\end{tabular}

Data are expressed as the mean \pm standard deviation $(\mathrm{P}>0.05)$. LDL-C, low-density lipoprotein cholesterol; HDL-C, high-density lipoprotein cholesterol; VLDL-C, very low-density lipoprotein cholesterol.

compared with the non-drinker and Turkish coffee groups $(445.9 \pm 346.9$ vs. $360.4 \pm 250.25$ and $322.1 \pm 182.4 \mathrm{ml} / \mathrm{day}$, respectively). However, herbal tea consumption was lower in the instant coffee group compared with the non-drinker and Turkish coffee groups $(17.5 \pm 50.33$ vs. $26.1 \pm 69.60$ and 27.0 $\pm 55.46 \mathrm{ml} /$ day; Table II).

Associations between coffee consumption habits and serum lipid levels. Mean serum lipid levels of all the subjects were as follows (in mM): TG, $2.2 \pm 2.68$; TC, $5.7 \pm 1.28$; LDL-C, $3.5 \pm 1.10$; HDL-C, 1.2 \pm 2.62 ; and VLDL-C, $0.9 \pm 0.52$. The levels of serum TG were higher in the instant coffee group $(2.7 \pm 3.87 \mathrm{mM})$ when compared with the non-drinkers $(2.0 \pm 1.10 \mathrm{mM})$ and Turkish coffee groups $(1.9 \pm 1.42 \mathrm{mM})$. Total cholesterol levels in the Turkish coffee drinkers $(5.8 \pm 1.33 \mathrm{mM})$ were higher compared with the non-drinkers $(5.7 \pm 1.32 \mathrm{mM})$ and instant coffee groups $(5.7 \pm 1.24 \mathrm{mM}$; Table III). The serum LDL-C levels in the non-drinkers, Turkish coffee and instant coffee groups were $3.5 \pm 1.18,3.7 \pm 0.97$ and $3.3 \pm 1.12 \mathrm{mM}$, respectively. Serum HDL-C levels were comparable amongst the groups; however, the mean VLDL-C level in the non-drinker group $(1.0 \pm 0.72 \mathrm{mM})$ was comparatively higher compared with the Turkish $(0.8 \pm 0.36 \mathrm{mM})$ and instant $(0.9 \pm 0.32 \mathrm{mM})$ coffee groups. Following adjustment of the results for confounding factors, including age, gender, smoking, BMI, black and herbal tea consumption, daily total energy, fat, polyunsaturated fat, monounsaturated fat, omega 3 , omega 6 , carbohydrate and fiber intakes, coffee consumption duration and habits, no statistically significant differences were identified in the serum lipid levels between the groups ( $\mathrm{P}>0.05$; Table III).

When the levels of serum lipids were compared with various coffee consumption habits, no statistically significant differences were observed with regards to the coffee density (dark, medium or light) and temperature (very hot, hot, warm or cold). Furthermore, mean levels of serum lipids were compared according to subject sugar/cream consumption and smoking status (Table IV). Serum TG levels in the subjects who consumed coffee with cane sugar were observed to be higher compared with the subjects who consumed plain coffee $(2.6 \pm 3.38$ vs. $1.8 \pm 0.89 \mathrm{mM})$. Furthermore, serum TG levels in individuals who consumed cream or a powdered substitute

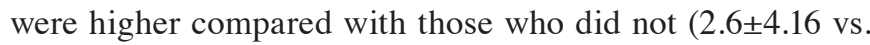
$2.2 \pm 1.34 \mathrm{mM}$ ). However, no statistically significant differences were observed in the serum lipid levels when comparing subjects who consumed cane sugar and cream/powdered substitute and those who did not $(\mathrm{P}>0.05)$. Similarly, no statistically significant differences were observed in serum lipid levels between smokers and non-smokers $(\mathrm{P}>0.05)$.

\section{Discussion}

To the best of our knowledge, the present study was the first to investigate the associations between Turkish and instant coffee with serum lipid levels in Turkish individuals. In addition, 
the present study reported the coffee consumption status of 122 Turkish individuals $(41.4 \pm 12.69$ years $)$ in a cross-sectional study.

One of the key findings of the present study was that Turkish and instant/soluble coffee consumption resulted in no significant alteration in the serum levels of TG, TC, LDL-C, HDL-C or VLDL-C in the study population following adjustment of the results for confounding factors. Consistent with this finding, Zargar et al (16) reported no significant changes in the serum levels of TC, LDL-C or non-HDL-C following café latte consumption in a study population of 49 adult subjects (34 females; mean age, 32.2 \pm 13.2 years). However, TG levels reduced significantly from a median of 0.85 to $0.84 \mathrm{mg} / \mathrm{dl}(\mathrm{P}<0.05)$. By contrast, the results of numerous studies investigating the effects of coffee consumption on serum lipid levels do not concur with the findings of the present study. Urgert and Katan (17) reported that the consumption of boiled coffee increased the serum levels of TC by $0.59 \mathrm{mM}$ and LDL-C by $0.36 \mathrm{mM}$, while consumption of filtered coffee increased the TC level by only $0.07 \mathrm{mM}$ and did not affect the LDL-C level. In addition, a study by Naidoo et al (18) indicated that the consumption of five cups of unfiltered Indonesian coffee per day resulted in a substantial increase in serum levels of TC $(0.33 \mathrm{mM})$ and TG $(0.20 \mathrm{mM})$. A meta-analysis of 14 randomized controlled trials indicated that the consumption of boiled coffee increased the TC and LDL-C serum concentrations in a dose-dependent manner, while the consumption of filtered coffee resulted in a relatively small alteration in serum TC levels (19). Thus, the method of coffee preparation and the quantity consumed have been demonstrated as important determinants of serum lipid levels. However, the daily volumes of coffee consumption for Turkish $(62.3 \pm 40.60 \mathrm{ml} ; 0.7 \pm 0.50 \mathrm{cup})$ and instant $(116.3 \pm 121.96 \mathrm{ml}$; $0.7 \pm 0.81$ cup) coffee in all the subjects were less compared with those reported in the aforementioned studies. Furthermore, the mean annual consumption of coffee by the Turkish population is relatively low $(0.4-0.7 \mathrm{~kg})$ per capita compared with other countries. Thus, the discrepancies between the present study and previous studies in the observed correlations between coffee consumption and serum lipid levels were hypothesized to be due to the relatively small quantities of coffee consumed by Turkish individuals.

A number of bioactive molecules within coffee have been identified as potential mediators of the previously reported increase in serum lipid levels, including diterpene, cafestol and kahweol, which comprise $\sim 1 \%$ of a single coffee bean (17). Alternative potential mediators include chlorogenic and caffeic acid, polyphenols, caffeine and caffeine metabolites, such as di- and mono-methylxanthines, flavonoids, melanoidins and furans, pyroles and maltol, in addition to a variety of fat-soluble compounds found in coffee beans (20). Diterpenes, in particular, are largely extracted from coffee beans by hot water, but are retained by a paper filter, which may explain why filtered coffee does not appear to affect cholesterol, whereas boiled Scandinavian, Turkish and Greek coffees do (17). There are a number of plausible biological mechanisms by which coffee compounds may affect serum lipid levels. In particular, cafestol has been shown to reduce the expression and activity of cholesterol $7 \alpha$-hydroxylase, which is the rate-limiting enzyme in the classic pathway of bile acid synthesis, in cultured rat hepatocytes and the livers of apolipoprotein (Apo)E3-Leiden transgenic mice (21). Inhibition of bile acid synthesis has been suggested as a possible mechanism underlying the cholesterol-increasing effect of cafestol. Previous studies have reported that the hypercholesterolemic effect of these components may vary depending on individual genetic variations $(22,23)$. Thus, different genotypes and genetic environments may be involved in the variations observed in the effects of coffee on serum lipid levels in different populations, as found in the current study. Furthermore, the results of studies investigating the effects of major sources of caffeine on serum lipid levels have been inconsistent $(24,25)$. Boekschoten et al (24) reported that the consumption of 750-1,000 $\mathrm{ml}$ decaffeinated coffee by 119 healthy students (60 male and 59 female) twice a day resulted in no significant alterations in serum levels of TC, LDL-C, TG and $\mathrm{ApoB}$ when compared with caffeinated coffee. In addition, a randomized controlled meta-analysis trial by Ricketts et al indicated that diterpenes such as cafestol, found in unfiltered coffee, increased the levels of serum cholesterol (25). In the present study, no subjects reported the consumption of any variety of decaffeinated coffee. Thus, comparisons between the serum lipid profiles of caffeinated and decaffeinated coffee drinkers were not possible.

Notably, the present study identified no statistically significant differences in the serum lipid levels when comparing subjects who consumed coffee with cane sugar and liquid/powder cream and subjects who did not add these agents ( $\mathrm{P}>0.05)$. Contrary to this observation, Cheung et al (26) suggested that the addition of flavoring substances, such as sugar and cream, to coffee resulted in significant alterations in the serum levels of TC, HDL-C and TG, but not in the levels of LDL. In the present study, the quantities of flavoring substances added to coffee were not recorded; thus, comparisons with other studies were not performed.

In addition, no statistically significant difference was observed in the serum lipid levels between subjects who smoked and non-smokers $(\mathrm{P}>0.05)$. Coffee consumption is strongly correlated with tobacco smoking. A study examining the associations between serum levels of TC and HDL-C with the consumption of Turkish coffee and cigarette smoking reported no association between smoking and the TC and HDL-C levels. However, boiled Turkish coffee consumption was independently associated with increased serum TC and HDL-C levels (27). In addition, Salonen et al indicated that high levels of coffee consumption were associated with a reduction in the serum levels of HDL-C in smokers, but increased levels of HDL-C were observed in non-smokers (28).

In conclusion, the results of the present study demonstrated that Turkish and instant coffee consumption did not significantly affect serum lipid levels. However, the correlations between coffee consumption habits and serum lipid levels require further investigation through epidemiological studies with a larger sample size, including different age groups and populations.

\section{References}

1. National Coffee Association (NCA): National coffee drinking trends. NCA, USA, 2012.http://www.ncausa.org/files/Market\%20 Research/NCDT2012_free_download.pdf. Accessed July 10, 2014. 
2. International Coffee Council (ICC): Trends in coffee consumption in selected importing countries. 109th Session. ICC, London, UK, 2012.

3. Bakuradze T, Parra G, Riedel A, et al: Four-week coffee consumption affects energy intake, satiety regulation, body fat, and protects DNA integrity. Food Research International 63: 420-427, 2014.

4. Cano-Marquina A, Tarín JJ and Cano A: The impact of coffee on health. Maturitas 75: 7-21, 2013.

5. Higdon JV and Frei B: Coffee and health: a review of recent human research. Crit Rev Food Sci Nutr 46: 101-123, 2006.

6. Corrêa TA, Rogero MM, Mioto BM, Tarasoutchi D, Tuda VL, César LA and Torres EA: Paper-filtered coffee increases cholesterol and inflammation biomarkers independent of roasting degree: a clinical trial. Nutrition 29: 977-981, 2013.

7. Miyake Y,Kono S, Nishiwaki M, Hamada H, Nishikawa H, Koga H and Ogawa S: Relationship of coffee consumption with serum lipids and lipoproteins in Japanese men. Ann Epidemiol 9: 121-126, 1999.

8. van Dusseldorp M, Katan MB, van Vliet T, Demacker PN and Stalenhoef AF: Cholesterol-raising factor from boiled coffee does not pass a paper filter. Arterioscler Thromb 11: 586-593, 1991

9. Brown CA, Bolton-Smith C, Woodward M and Tunstall-Pedoe H: Coffee and tea consumption and the prevalence of coronary heart disease in men and women: results from the Scottish Heart Health Study. J Epidemiol Community Health 47: 171-175, 1993

10. Silvério Ados S, Pereira RG, Lima AR, Paula FB, Rodrigues MR, Baldissera L Jr and Duarte SM: The effects of the decaffeination of coffee samples on platelet aggregation in hyperlipidemic rats. Plant Foods Hum Nutr 68: 268-273, 2013.

11. Cai L, Ma D, Zhang Y, Liu Z and Wang P: The effect of coffee consumption on serum lipids: A meta-analysis of randomized controlled trials. Eur J Clin Nutr 66: 872-877, 2012.

12. Aro A, Teirilä J and Gref CG: Dose-dependent effect on serum cholesterol and apoprotein B concentrations by consumption of boiled, non-filtered coffee. Atherosclerosis 83: 257-261, 1990.

13. Jossa F, Krogh V,Farinaro E, et al: Coffee and serum lipids: findings from the Olivetti Heart Study. Ann Epidemiol 3: 250-255, 1993.

14. Lopez-Garcia E, van Dam RM, Willett WC, et al: Coffee consumption and coronary heart disease in men and women: A prospective cohort study. Circulation 113: 2045-2053, 2006

15. Rebello SA and van Dam RM: Coffee consumption and cardiovascular health: Getting to the heart of the matter. Curr Cardiol Rep 15: 403, 2013.

16. Zargar A, Auttapibarn C, Hong SH, Larson TJ, Hayworth KH and Ito MK: The effect of acute café latte ingestion on fasting serum lipid levels in healthy individuals. J Clin Lipidol 7: 165-168, 2013.
17. Urgert R and Katan M: The cholesterol-raising factor from coffee beans. Annu Rev Nutr 17: 305-324, 1997.

18. Naidoo N, Chen C, Rebello SA, et al: Cholesterol-raising diterpenes in types of coffee commonly consumed in Singapore, Indonesia and India and associations with blood lipids: A survey and cross sectional study. Nutr J 10: 48, 2011.

19. Jee SH, He J, Appel LJ, Whelton PK, Suh I and Klag MJ: Coffee consumption and serum lipids: a meta-analysis of randomized controlled clinical trials. Am J Epidemiol 153: 353-362, 2001

20. Lee C: Antioxidant ability of caffeine and its metabolites based on the study of oxygen radical absorbing capacity and inhibition of LDL peroxidation. Clin Chim Acta 295: 141-154, 2000.

21. Wahrburg U, Martin H, Schulte H, Walek T and Assmann G: Effects of two kinds of decaffeinated coffee on serum lipid profiles in healthy young adults. Eur J Clin Nutr 48: 172-179, 1994.

22. Nilsson LM, Wennberg M, Lindahl B, Eliasson M, Jansson JH and Van Guelpen B: Consumption of filtered and boiled coffee and the risk of first acute myocardial infarction; a nested case/referent study. Nutr Metab Cardiovasc Dis 20: 527-535, 2010.

23. Post SM, de Roos B, Vermeulen M, et al: Cafestol increases serum cholesterol levels in apolipoprotein E*3-Leiden transgenic mice by suppression of bile acid synthesis. Arterioscler Thromb Vasc Biol 20: 1551-1556, 2000.

24. Boekschoten MV, Engberink MF, Katan MB and Schouten EG: Reproducibility of the serum lipid response to coffee oil in healthy volunteers. Nutr J 2: 8, 2003

25. Ricketts ML, Boekschoten MV, Kreeft AJ, et al: The cholesterol-raising factor from coffee beans, cafestol, as an agonist ligand for the farnesoid and pregnane $\mathrm{X}$ receptors. Mol Endocrinol 21: 1603-1616, 2007.

26. Cheung RJ, Gupta EK and Ito MK: Acute coffee ingestion does not affect LDL cholesterol level. Ann Pharmacother 39 1209-1213, 2005.

27. Jansen DF, Nedeljkovic S, Feskens EJ, Ostojic MC, Grujic MZ, Bloemberg BP and Kromhout D: Coffee consumption, alcohol use, and cigarette smoking as determinants of serum total and HDL cholesterol in two Serbian cohorts of the Seven Countries Study. Arterioscler Thromb Vasc Biol 15: 1793-1797, 1995.

28. Salonen JT, Happonen P, Salonen R, et al: Interdependence of associations of physical activity, smoking, and alcohol and coffee consumption with serum high-density lipoprotein and non-high-density lipoprotein cholesterol - population study in eastern Finland. Prev Med 16: 647-658, 1987. 